\title{
LA FILOSOFÍA POSTESTRUCTURALISTA FEMINISTA: DESARROLLO DE LA IDENTIDAD DE LA ACADÉMICA MEXICANA COMO UNA PRÁCTICA EDUCATIVA DE LA INVESTIGACIÓN
}

FEMINIST POSTSTRUCTURALISM PHILOSOPHY: DEVELOPMENT OF THE IDENTITY OF THE MEXICAN ACADEMIC AS AN EDUCATIVE PRACTICE OF THE INVESTIGATION

\section{RESUMEN:}

Este artículo se basa en un estudio de la identidad propia de la mujer académica en universidades mexicanas desde una perspectiva feminista y postestructuralista. De esta forma, se pretende indicar la formación de la investigadora en este contexto a través de un trabajo de campo que estudiará con profundidad los diferentes factores que intervienen en ello.

\section{Palabras claves:}

Postmodernidad feminismo.

\section{Abstract:}

This article is based on a study of theidentity of the academic woman in Mexican universities from a feminist and poststructuralist perspective. In this way, it aims to indicate the career of the researcher woman in this context throughout a field work which will study deeply the different aspects that take part on it.

\section{KEY WORD:}

Postmodernism, woman, university, 
En cualquier enfoque teórico, filosófico y metodológico que uno se posicione desemboca siempre en un camino tortuoso y desaseado porque la apuesta es entender no solo lo visible sino también lo invisible de las identidades de la mujer académica mexicana. La propuesta es identificar el cómo se constituyen y reconstituyen estas identidades a partir de varios textos, pero principalmente a partir de sus propios relatos de vida. Como autora estoy llamada a desentrañar esos episodios donde la ruptura irrumpe en esas preconcepciones y presupuestos que reflejan toda una serie de contradicciones, juicios, prejuicios y percepciones que dieron lugar a posicionamientos a veces al centro y otras al margen del debate. Se arremete sobre estos temas en todo el cuerpo de la obra, pero en este capítulo se confina en presentar un esbozo clave de los temas relevantes a la teoría, la filosofía y la metodología circunscritas al proceso de la investigación y la redacción de este trabajo.

Para empezar y de manera abreviada la autora está obligada a explicar qué le atrajo a este enfoque ideológico y filosófico adoptado en esta investigación y que ampliamente se suscribe a un feminismo poststructuralista, cómo fue afectando la forma en que la investigadora aborda estos ejes conductores del proceso de la investigación. Posteriormente nos enfocaremos en otros momentos significativos y relevantes a la propia formación de la investigadora. También en este capítulo nos ocuparemos de plantear el plan que siguió la investigación, los métodos que se aplicaron para recolectar la información, el proceso de traducción, y desde luego se consideran ciertos temas relacionados a la ética, el análisis, la redacción y en particular lo pertinente al capítulo destinado a la metodología. En el fondo también se intenta presentar un panorama de la academia en México de tal suerte que el lector se sumerja en el contexto en el cual se condujo esta investigación y la relación de la autora hacia su propia obra.

UN CAMINO APLICADO EN LA INVESTIGACIÓN EDUCATIVA Y EL FEMINISMO POSTSTRUCTURALISTA

Todo empieza durante los seminarios suscritos al programa de doctorado en filosofía y que se imparte en CARE (Centro de Investigación Aplicada a la Educación) por sus siglas en inglés en la Universidad de East Anglia en Norwich, Gran Bretaña, que un sinnúmero de temas empezaron a surgir en relación al tipo de investigación que los candidatos a doctorado debían de producir. También las lecturas de los diferentes manuales de apoyo tales como "Accediendo a los términos de la investigación", (1994) mismos que propiciaron una idea general a los estudiantes respecto al panorama de la investigación cualitativa, es que ciertos tópicos empezaron a despertar cierta curiosidad a la investigadora. De acuerdo a los diarios de notas que como investigadora (de primer semestre en el CARE) estábamos obligadas a elaborar para el 17 de octubre de 2002 el tema seleccionado se orientaba hacia "El proceso de la enseñanza académica". Durante las asesorías con una de las supervisoras, ya que se nos asignan dos, una
ISSN: 1885-3625 al de Culturas y Literaturas, abril 2011

de sus sugerencias fue la empezar la revisión de la literatura tomando en cuenta ciertos autores y autoras tales como McWilliam, Spivak, Lather, Gore, y Bell Hooks. Subsecuentemente, fue necesaria la lectura también de Foucault, Derrida, Lyotard y Bourdieu. Fue así como fue tomando forma mi propia perspectiva teórica. Aunque el desempeño y el entrenamiento son aspectos que se relacionan con la vida académica dentro de un ángulo propio, el interés se centraba más en los aspectos subjetivos como sus vidas personales y sus experiencias pero más bien todo lo que subyace en el desarrollo de la subjetividad además del rol implicado en la teoría, etc. En un primer momento las preguntas que de por si fueron de gran provocación y de intriga son las siguientes:

¿Están satisfechas con su vida académica?

¿Fueron cambiando sus valores conforme sus carreras progresaron?

¿Cuáles fueron sus actitudes y compromisos en relación a su práctica como

educadoras?

¿Se están cumpliendo sus metas y sus expectativas?

¿Se reconocen incluidas o excluidas -dentro o fuera- de la institución?

¿Se sientes satisfechas con sus ingresos?

¿Están contentas con su desarrollo personal? ¿Identifican algunos temas relacionas con la identidad en su trabajo?

¿Tienen libertad de expresión y son libres de ser críticas hacia la institución o el sistema?

¿Cómo perciben su calidad de vida?

¿Están satisfechas con su desarrollo profesional?

Todo esto se constituyó en una serie de cuestionamientos que fuenecesario acotar para llegar a un enfoque real que condujera a una investigación temática. Un seminario que impactó fuertemente mi curiosidad y por supuesto que amplió mis cuestionamientos fue el que presentó Ted Liu, un colega del doctorado y cuya investigación se enfocó estrictamente en una revisión teórica de las filosofías de la educación. El seminario se realizó en noviembre del 2002 y lo tituló, “La Ilustración, razones y subjetividad: imaginándose un acercamiento educativo desde la era de la postmodernidad". Fue entonces cuando tomé la determinación de anclar mi investigación en la perspectiva de la postmodernidad y adoptar ciertos fundamentos teóricos para mi investigación en relación al tema de la identidad de la académica mexicana. Esto también conllevó a ampliar más mi comprensión de una disciplina la cual de acuerdo a mi percepción es la madre de todas las disciplinas - la filosofía. Cabe recordar que en México tomé un diplomado de introducción a la filosofía general en una institución privada, ITESM en Monterrey, lo cual me dio un panorama general, así que ya para entonces en la UEA [University of Easta Anglia], tomé otro curso express por mi cuenta que acomet leyendo diferentes textos empezando desde luego con aquellos que se recomiendan para principiantes.

A partir de aquí empezaron a surgir una serie de dilemas y tensiones como consecuencia de las contradicciones que se fueron identificando por la brecha enorme 
existente entre la práctica y la retórica de la teoría del pensamiento de la Ilustración. El concepto de la 'educación liberal' en sí misma empezó a tambalearse. Madeleine Arnot, académica de la universidad de Cambridge, expuso una serie de ideas y teorías durante un seminario público el 28 de noviembre del 2002 que fue sumando a la comprensión siempre expandiéndose e introduciendo nuevos temas como aquellos relacionados con la ciudadanía, la democracia liberal y el feminismo crítico. Esto cayó en terreno fértil y contribuyó en una comprensión más amplia sobre los aspectos políticos especialmente los relacionados a la obligación del estado en propiciar el estado de bienestar del ciudadano. Ya para entonces no solo se identifican sino que también se localizan las contradicciones tácitas a la ideología de la Ilustración, la democracia liberal, la educación liberal, aunque de manera superficial.

Me intrigaban los retos del modelo propuestos por la educación liberal porque se fundamentan en una base que parte del discurso humanista y que presuponen algunos supuestos tales como lo que sugiere Weedon, “La propuesta es que en esencia en el corazón del individuo el cual es único e irrepetible, fijo y coherente y por definición su naturaleza es la de una consciencia racional unificada de una política filosófica liberal" (1997: 32). Acto seguido el efecto de la introspección me sumergió en una crisis existencial desde la propia subjetividad como investigadora.

Mi propia subjetividad se zarandeó bajo mis pies violentamente en relación a los temas del ser, la identidad, el yo y la subjetividad. Más aun las convicciones cristianas y la fe fueron probadas y como creyente, ya que en el pasado entendía que la fe era un mero ejercicio de imitar y desarrollar las mismas actitudes y valores prescritos en las Escrituras: ¡Imitar a Jesucristo asumiendo el mismo rol y desarrollar una identidad similar a la suya! (De acuerdo a un anteproyecto presentado el 10 de octubre del 2002 con el título "Salud mental y valores para transformar la identidad del maestro en la educación superior en México").

El objetivo de esta obra para entonces se circunscribía en dar cuenta acerca del desarrollo de la académica intelectual en Tabasco, México, pero con un enfoque inteligible de las condiciones que influyeron en dar forma a esa identidad fragmentada, desmembrada, 'desplazada/reemplazada' argumenta Lather (1991: 118) de la educadora femenina desde una perspectiva crítica feminista. Este tema si que atrajo mi atención para empezar desde que empecé a cuestionarme acerca de mi propia identidad y cómo el 'otro' me percibe. Ya para entonces reconocía que era poseedora de una identidad incoherente, heterodoxa, incongruente y contradictoria y sin la posibilidad de darle una explicación a su origen. Todavía se me complican más las cosas cuando me tropiezo con el mega concepto de la subjetividad. Quizá algunas razones que justifiquen el acercamiento a este concepto se derivan de la constante necesidad intrínseca que como individuos normales posee uno en esa lucha
RSAta Internacional de Culturas y Literaturas, abril 2011

constante de presentarse 'aprobado' ante el mundo, además de consistente y coherente comoinvestigadora, es decircomo sujeto. La búsqueda dela consistencia identitaria como investigadora en la práctica de los valores y la necesidad de convertirme en una crítica auténtica y efectiva (y evitar el juicio o la difamación) justifican el recorrido deesta odisea. En esa búsqueda es que me tropiezo con el postulado de Derridá (1976), "No hay escritura fuera del texto," o más bien "Fuera de la escritura no hay texto" a esto me subscribo de inmediato ya que impulsa una fuerza de ruptura (Butler, 1997) liberadora del desaseo en que me encontraba. Aunque confieso que no fue un proceso inmediato sino más bien lento y doloroso.

Aunado a este episodio problemático en vano resultaba sustraerse de la imperiosa necesidad de producir un recuento coherente de las colaboradoras que tan gentilmente habían contribuido con sus relatos de historias de vida en esta obra. Detectar que la 'verdad' era escurridiza, contradictora e inconsistente era visible y sin duda evidente. Es por eso que preferí el anonimato y la invisibilidad como solución viable para fundamentar los argumentos a partir de los datos recolectados de las historias de vida. Aunque todas las colaboradoras dieron su consentimiento para abrir sus verdaderas identidades, una en particular, Esther Orozco estuvo dispuesta a que su identidad no se ocultara, lo que me parece afortunado porque ocultar la identidad de alguien de su estatura habría resultado imposible o muy difícil.

El seminario que impartió Madeleine Arnot de Cambridge fue crucial ya que me motiva en fundamentar y abstraer del discurso feminista y aprovechar las propuestas que esta perspectiva propone. Para febrero de 2003 el Profesor Nigel Norris presentó un seminario donde analizamos las características y requisitos que debíamos seguir a la hora de redactar la tesis doctoral por lo que ya debía a estas alturas identificar temas o tópicos más específicos. Ya para marzo del 2003 contemplaba incluir las teoría feministas críticas para construir el marco teórico de la investigación que me proponía realizar. Sin embargo inicialmente me embargaba un escepticismo el fundamentar mi proyecto en los argumentos y fuentes provenientes del discurso feminista mucho influenciado por el radicalismo y la poca efectividad política, según mi percepción, de las feministas en México. Pero fueron surgiendo evidencias contundentes que indicaban de que si el tema a investigar se enfocaba en el desarrollo de la mujer académica y la transformación de su subjetividad, el feminismo era un discurso clave e inevitable a la hora de redactar el marco teórico y contextualizar lo político. Aunado a este escepticismo mi temor también se fundamentaba en que el feminismo totalmente entraba en contradicción con mis principios provenientes de una ortodoxia cristiana.

De esto me habían alertado fuertemente amigas y conocidos y en contra de la filosofía postmoderna pero en general en contra de la filosofía porque temían me extraviara o traicionara mis convicciones o peor aun mi fe. En un principio yo misma temía que 
así fuera y que esto me llevara a un vacío, frustración o en un desvío intelectual y espiritual total. Eventualmente empecé a vislumbrar más bien que la filosofía y en especial el discurso de la postmodernidad me serían útiles como herramientas para abstraer y desenmascarar los discursos provenientes del Humanismo y la Ilustración, un paradigma que de por si promete mucho pero que cumple casi nada en términos de justicia social, libertad y esperanza en la comunidad globalizadas. Por demás interesante fue una las colaboradoras quien me hizo reconocer lo implicada que ya de por si estaba en el discurso feminista. Durante la entrevista que sostuve con Diana, reconoció que ella misma se había convertido en feminista a partir de las múltiples conversaciones que en el pasado habíamos sostenido: "Fue más bien gracias a ti que hoy te debo que sea feminista y hoy sea una defensora de este discurso como investigadora y de ahí que imparto conferencias en México y fueras del país e investigo acerca de la violencia doméstica y la mujer golpeada. Además recientemente estoy investigando junto con los alumnos de la licenciatura en educación el tema de género y educación y cómo se desarrolla y adopta el feminismo en las aulas". De hecho Diana me confrontó con mis contradicciones y fue a través de estas conversaciones informales que empecé a tomar conciencia de las tensiones polémicas en que los debates religiosos, la moral y el liberalismo con frecuencia me acorralaban. "Solo te escuchaba y no quise ser grosera contigo o juzgarte mal pero por un lado te percibía muy liberal pero por el otro tu trasfondo cristiano hacía que te traicionaras".

Cabe mencionar que Diana es una buena amiga quien también es una profesional de la psicología conductista quien después abrazó la teoría cognoscitiva. En el pasado en la realidad familiar también surgieron estos debates porque me oponía rotundamente al discurso feminista. Provengo de una familia donde somos 3 hermanas y un hermano menor pero me ubico como la segunda de las mayores, la hermana sándwich entre la mayor y la menor de 2 hermanas. Mi madre auguraba un futuro prometedor y de grandes expectativas para mis hermanas pero por ser yo la hija desordenada e indisciplinada según ella nunca iba a lograr el éxito. A mi hermana mayor la definiría como la mujer tradicional realizada como madre y esposa de 4 hijos hasta que su suerte la abandonó y su esposo se convirtió en un número estadístico más entre los desempleados después de haberse desempeñado como un flamante ingeniero de la industria petrolera simplemente fue despedido injustificadamente. Fue el turno de $\mathrm{mi}$ hermana al convertirse en la que generaba el sustento dejando las labores del hogar y buscar empleo en una empresa y desempeñarse como secretaria ejecutiva y consejera financiera. Mihermana menor es solteray se desempeña profesionalmenteenlamedicina muy exitosamente. Recuerdo que en una ocasión tuve el atrevimiento de aconsejar a mi hermano menor sobre lo arruinado que veía su futuro sino ponía en orden su familia y para mi sorpresa tuve como respuesta atinada de su parte de que me guardara mis comentarios ya que me identificaba como "una total contradicción". Sin embargo ahora
RSAta Internacional de Culturas y Literaturas, abril 2011

que reflexioné en esta conversación, llegué a la conclusión de que a menudo caigo en el hábito de la racionalidad feminista, pero de manera irreflexiva o inconsciente. Ha sido a partir de la lectura de la teoría y perspectiva feminista que ahora entiendo el origen de mis propias "contradicciones", hábitos y prejuicios. Esto es un valor agregado del propósito que conlleva el proceso de definir el marco teórico de esta investigación. En la siguiente sección espero abstraer algunas ideas a consideración del lector y de cómo influyeron en el proceso de este proyecto. Algunas de las razones por las que sospechaba de la teoría feminista las atribuyo a mis suposiciones al igual que a mis prejuicios y de las que a veces resulta difícil sustraerse toda vez que las suposiciones se ocultan en el subconsciente y hasta que se confrontan y examinan es que se puede avanzar en el terreno de la transformación social y de la subjetividad. La abstracción y revisión teórica es un proceso que contribuye en esta substracción de suposiciones y reconozco que fue un ejercicio clave en mi desarrollo personal ya que dio lugar a cultivar una subjetividad movible pero a la vez fuerte. Me refiero a una movilidad resistente a los embates marcados por restricciones de la esencialidad.

Expuesta esta esencialidad se refiere a esa burda creencia de la existencia de una esencia pura y verdadera. Un ejemplo nos lleva a pensar en la posibilidad de que el hombre sea diferente de la mujer en el sentido de que esencialmente esté capacitado para asumir roles y funciones diferentes a los de la mujer y por lo mismo regirse o adherirse a reglas de conducta diferentes. Así que la esencialidad puede servir de avance pero también de trampa para las feministas. Más aún desde la postmodernidad se puede incurrir en esto al tratar de fundamentar el argumento de la diferencia entre hombre y mujeres sino ¿cual sería el debate político de las feministas que parte de una raíz en contra de la esencialidad? Ahí radica el misterio en tanto se acuñan nuevos lenguajes respecto a la esencialidad mientras el suspenso continúa. De acuerdo a la investigación realizada por Gabriela Delgado se encontró que las académicas en la UNAM el $85 \%$ consideran todavía que el tener una relación de pareja le da un propósito pleno de vida y el $70.2 \%$ sostienen que esto es lo que las hace mujer (2004: 390). Sin embargo también encontró que esto contradice totalmente la opinión que sostienen las académicas en relación a los debates acerca de la autorrealización como mujeres en la academia. Quizá esta sea la experiencia de la mayoría de las académicas sin que jamás hayan reflexionado al respecto, no por esto dejan de ser agentes de cambio o hayan dejado de sufrir transformaciones en sus identidades. Es probable que las relaciones de poder sean el motor que promueve el éxito y por lo mismo lo alcancen a un alto precio. En su mayoría las colaboradoras sostienen que ellas son la primera generación de mujeres en sus familias haber asistido exitosamente a la universidad y haber asegurado una posición en la academia y esto para ellas es de por un gran 'éxito'. Esto desde luego es un reflejo vago y nocivo de la justicia que prevalece en México en cuanto a la agenda de género se refiere ya que la educación superior sigue 
siendo el privilegio de una minoría. En ese sentido Faith sugiere que "Las feministas estaríamos de acuerdo en que el éxito solo se da en relación a ciertos temas, tiempos y espacios, y de ninguna manera son finitos, permanentes o universales de tal suerte que no se pueden catalogar como simples episodios revolucionarios". (1994: 58)

Es de contender que esta resistencia pasiva ha generado ningún cambioético o político argumento sino más bien subyace un largo proceso. Con toda claridad se vislumbra la necesidad de un feminismo en contra de las esencialidades y esta definición la recupero de lo propuesto por Faith (1994: 37) de nueva cuenta: "Feminismo es una resistencia la invisibilidad y al silencio. Es el reconocimiento de que la resistencia a las relaciones de género son tanto integrales a y a la vez diferente de otras resistencias de injusticia global. El feminismo es el deseo de la voluntad de enfrentarse a las disparidades de género como una realidad universidad antinatural, a un proceso estructural que afecta tanto lo femenino como lo masculino y que puede deconstruirse a partir de una toma de conciencia y de cambio social. La resistencia feminista se articula a través de los movimientos de mujeres y de acciones individuales, incluyendo el rechazo y la separación".

Pero ¿cómo se supone actuar una persona que jamás ha experimentado el tipo de libertad al que se requiere para identificar el poder? Quiero decir el tipo de libertad que "radica en una capacidad de descubrir los vínculos históricos entre ciertos modos de auto comprensión y modos de dominación y el resistir a todas estar formas desde las cuales hemos sido clasificadas e identificadas por los discursos dominantes. Esto significa descubrir nuevas formas de comprendernos a nosotros mismas y al otro rechazando el aceptar las caracterizaciones de la cultura dominante de nuestras prácticas y deseos sino redefinirlos desde dentro de las resistencias culturales" (Sawicki, 1988: 186). El problema radica en que la mayoría de las académicas se encuentran más preocupadas por las actividades cotidianas de su quehacer docente como el preparar las lecciones que es muy remoto que se den tiempo para ellas, o se sienten a identificar las fuentes de dominio u opresión y si se interesan en reconocerlas como tales definitivamente. Más bien percibo que las instituciones de educación superior son espacios en general donde la posibilidad de transformación puede ser un proceso lento y limitado (Gil Antón, M., 2003, Anort, M., 2002, Blackmore, J., 1999). Esto suena por demás desconcertante ya que cualquier esfuerzo que como académicas pueden aspirar obtener en relación a los temas de género provendrá de iniciativas independientes e individuales. Son claras las exigencias cada vez más fuerte a que las académicas se conviertan también en investigadoras, en que publiquen y accedan a niveles de postgrados más elevados y solo las que son más fuertes son quienes se someten a estas demandas. Es por eso mi inclinación al final hacia el feminismo as como el postestructuralismo y lo que más me motiva en la actualidad es la posibilidad
RSAta Internacional de Culturas y Literaturas, abril 2011

de manejar conceptos tales como habitus (Bourdieu, 1977), el de prácticas discursivas (Foucault, 1972) y el de la performatividad de J. Butler (1997) y así entender además de analizar las diferentes identidades que la académica mexicana asume en diferentes etapa de su vida.

La perspectiva del postestructuralismo "Carece de un significado único, más bien se aplica a un rango de posicionamientos teóricos dentro y desde los postulados de J. Derrida (1973, 1976), J.M. Lacan (1977), J. Kristeva (1974르, 1981, 1986), L. Althusser (1971) y M. Foucault (1978, 1979, 1979a , 1981, 1986)" (Weedon, C., 1997: 19). Sobresale en la "Teoría postestructuralista el factor común del análisis de las organizaciones sociales, los significados sociales, el poder y la consciencia individual es el lenguaje. El lenguaje es el lugar donde se dan todas las formas actuales y posibles de organización social así como la posibilidad de que se definan y debatan las consecuencias sociales y políticas. Además es el lugar donde también se construye nuestro sentido del ser y nuestra subjetividad" (Ibíd. 221). Para entender cuáles son las funciones del lenguaje es necesario recurrir al concepto de la deconstrucción aunque este término se resiste a una definición pero escogemos el uso que Derrida le atribuye por su habilidad de "abrir" significados, situaciones y posibilidades. Es con ese sentido que se emplea en esta obra.

Hebdige afirma que, "Si la postmodernidad significa poner a la palabra en su lugar.. si esto significa apertura al discurso crítico o por las líneas de la discusión y debate que en el pasado eran prohibidas, de evidencias inadmisibles en el pasado para que se formulen preguntas nuevas y diferentes y surjan otras voces que las produzcan; si esto significa la apertura de espacios institucionales y del discurso en el cual se desarrollen identidades más fluidas y con pluralismo social además de sexual; si esto significa la erosión de triangular las formaciones de poder y conocimiento con el experto en la cúspide y las masas en la base, si, en el trabajo, ensancha nuestro sentido colectivo (y democrático) de posibilidad entonces me declaro como postmoderna" (1989: 226). De igual manera desde esa postura se adopta en esta obra.

Para mí el postestructuralismo posibilita la "apertura de espacio" (Derrida, 1990: 82) ya que es donde inicia la crítica fructífera. Como sugiere MacLure, las aperturas pueden vislumbrarse como la "trasgresión o violación de las fronteras que marcan y protegen los territorios del conocimiento experto o elitista; también como el desmembrar los discursos magistrales y las políticas textuales para exhibir sus artificios del poder/ conocimiento; como la liberación de la posibilidad de la certidumbre muerta de la razón de la ilustración; como la fractura de los dualismos malignos de la identidad que margina al 'otro' (negro/blanco, investigador/investigado, mujer/hombre, heterosexual/gay); como la apertura al cuestionamiento de los discursos institucionales que definen los límites del sujeto que habla antes de que ella o él hable" (1997: 6). 
El leer la definición de Lyotard (1984) acerca de la postmodernidad como un posicionamiento de "incredulidad de los metarrelatos" es un concepto que trajo mucha paz mental, porque contrario a la popular lectura que es equivocada, es una posición saludable de escepticismo/incredulidad y no una negación total o de repudio de los metarrelatos. Desde luego que para algunos el postestructuralismo y la deconstrucción en "vez de arrojar luz, dificulta ver la cosas con claridad" (Stronach, I., MacLure, M., 1997: 5). Nos acercamos más a su afirmación “Aunque se interprete como un total abandono del proyecto de la ilustración por la emancipación y la racionalidad autónoma del sujeto humanizado, esa tarea en realidad queda fuera y profundamente dentro de su lógica, al forzar un espacio a nuevas preguntas acerca de la identidad, humanidad o de agencia"

\section{EVOLUCIÓN DE LAS PERSPECTIVAS METODOLÓGICAS PRINCIPALES}

La necesidad de presentar un proyecto de investigación para el 27 de marzo del 2003 me obligó a enfocarme en ciertos temas y a adoptar una posición más sólida en el discurso feminista desde una perspectiva postestructuralista. De hecho el titulo dado al proyecto fue: Género, educación y ciudadanía: el 'yo' dividido. Inicialmente pensé que el objeto de este proyecto se centraría en la familia como el grupo que más influye en la formación de las identidades individuales y la subjetividad pero muy pronto me di cuenta de que era demasiado ambicioso el tratar de entender cómo es que la familia le trasmite los valores y creencias 'visibles' en sus vidas a los sujetos. Por las mismas razones me interesó mucho el emplear las historias de vida como un método cualitativo de investigación. Goodson (2001: 1) presenta muy bien algunas de estas razones de emplear las historias de vida como método al igual que Erben (1998b: 1): "Explícitamente reconoce que las vidas no son comparta mentalizadas herméticamente en un sentido como por ejemplo, la persona que está en el trabajo (el yo profesional) y el que está en casa (el yo padre/niño/pareja) y que consecuentemente, cualquier cosa que nos suceda en un área de nuestras vidas impacta potencialmente sobre las demás además de de que tiene una suerte de implicaciones también Reconoce que existe una relación interactiva crucial entre las vidas de los individuos, sus percepciones y experiencias, sus contextos y eventos históricos sociales.

Aporta evidencias para demostrar como los individuos negocian sus identidade $\mathrm{y}$, en consecuencia, experimentan, crean y definen las reglas y los roles del mundo social en el que viven". Así que la idea fue la de entrevistar a 15 colaboradoras informantes para producir sus historias de vida, biografías o autobiografías. Fue posible obtener las historias de vida por medio de entrevistas conducidas en español. Una vez transcritas y traducidas al inglés, el análisis arrojó algunos temas específicos. El hacer investigación cualitativa para fundamentar los argumentos que me interesaba
Rest: 18853625 a de Cultras y Literaturas, abril 2011

investigar en el proyecto fue necesario reconocer que el proceso sería desaseado y complicado. No solo porque debía ser estratégica sino porque tenía que ser además creativa en el diseño de la investigación y seleccionar la metodología que mejor se adecuara. La justificación que sostiene esta perspectiva científica era el entender algunas de las condiciones que posibilitan el hecho de que aunque las mujeres sean el número mayormente representadas en la planta docente del sistema educativo mexicano, éstas tengan una representación baja y poco privilegiada en cuanto a igualdad, inclusión y compensación económica se refiere (SEDESOL, 2005). La perspectiva de las historias de vida también ofrecen la posibilidad de identificar y entender los sentimientos y emociones que las académicas asocian a los éxitos en su carrera, su logros, las fuente de placer, su contentamiento, limitaciones, exclusión, marginación, discriminación invisibilidad, opresión, desigualdad, injusticia y demás. Además, esta perspectiva también me permitió entender las condiciones en que impacta directamente en el proceso de generar una experiencia de enseñanza y aprendizaje no solo en relación a la infraestructura y el currículo, sino también en relación a las vidas de aquellos que intervienen directamente en el proceso: quienes enseñan y quien aprenden. Esta metodología permite localizar esas condiciones sociales que mantienen a las académicas en la educación superior desplegar todo su potencial como intelectuales, incluyendo la arena política. Lo que entiendo como "intelectual" se refiere a un sentido amplio de la palabra es decir aquellas que han obtenido un grado de doctorado, pero también aquellas que entienden su identidad y posicionamiento desde una autorreflexión crítica. El énfasis puesto en los grados de doctorado se refiere básicamente por el hecho de que aquellas que alcanzan algún tipo de éxito en la vida académica necesitan estos grados. La autorreflexión crítica que conduce a una conciencia política o más aún a una participación política fue crucial para entender el concepto de "intelectuales". Busqué por entender las razones del porqué muchas mujeres se excluyen ellas mismas de participar en la esfera política en casi todos los niveles al investigar sus vidas y así como su subjetividad desde el discurso académico. Las historias de vida como metodología es un instrumento poderoso para hacer estas interrogantes ya que te permite la posibilidad de entender cómo el poder de las relaciones de poder y las jerárquicas funcionan individualmente en sus vidas.

Las historias de vida son útiles aquí por las interrogantes que nos ocupan desde contextualizar y reportar acerca de las condiciones y circunstancias que prevalecen en las universidades mexicanas. Las historias de vida pueden emplearse como "Punto de entrada hacia un desarrollo más profundo acerca de la construcción de la subjetividad" (Goodson, I., 2003: 29). En cierto sentido las historias de vida "proveen un espacio de respiro lejos de lasinfluencias del poder" (Goodson, 2003:31). En México secarece de una tradición de aproximarse a las profesoras académicas para preguntarles que expresen sus pensamientos y opiniones acerca de ellas y sus circunstancias. Quizá a eso se deba 
el porqué aquellas que fueron entrevistadas expresaron un deseo abierto de que se emplearan sus nombres y así asumir el derecho de autoría de sus relatos. Sin embargo, como investigadora capaz de percibir los riesgos potenciales conducentes a eventuales problemas, me vi obligada a proteger sus identidades y por eso escogí el anonimato. La intención de guardar en el anonimato sus identidades es la de mantener intacto e relato y así poder emplear sus datos para fundamentar el argumento principal de la investigación, de que la formación de la identidad es un proceso que se constituye y reconstituye cada vez que hablamos y pensamos, de ahí que la identidad sea "precaria, contradictoria y en proceso" (Weedon, 1997: 32). Una de las participantes en lugar de esto propuso que su identidad y nombre verdadero podía revelarse, sin embargo cuando tuvo la oportunidad de revisar la versión final de su historia, se sintió incómodo con los datos que le presenté porque la representaban como alguien contradictoria. La historia relatada en los relatos de vida se expresaron originalmente en español y luego se tradujeron al inglés para esta investigación. Tuve toda la libertad como investigadora qué traducir y cómo traducirlo y aunque las informantes inicialmente expresaron su deseo de que las nombrara en la tesis, cuando les presenté las transcripciones de los datos, no hubo mayor reacción o respuesta. Podemos entender quizá sin sorpresa alguna ya que no quisieron involucrarse íntimamente en cada etapa del proceso de la investigación. Como investigadora eso representó un dilema inevitable por estar dentro y ser parte de la investigación y me refiero a la no representatividad, en particular cuando se seleccionan eventos claves para el análisis. Esto todavía más acentuó mi posición, el poder sobre la información y la responsabilidad como investigadora.

\section{Historias de VIDA DESDE EL TEXTO, UNA METOdología poststrUCtURALISTA FEMINISTA}

En el siguiente capítulo de la investigación se proveen las historias de vida cabalmente construidas de las participantes y así hacerlas visibles al lector, aun cuando es el investigador quien les confiere esa visibilidad y escoge qué forma darles. Esto sin duda alguna es una posición incómoda pero a la vez inevitable por ser un aspecto de poder del investigador. Lo que se presenta es inevitable, una combinación de lo que se me dijo, de lo que escuché y lo que escogí presentar. Las instantáneas que se presentan son necesariamente "un tejido de lo que se sabe y lo que se desconoce lo cual es lo que no es el saber" (Spivak, 1987: 78). Este saber se capta del desorden de las narrativas textualizadas lo cual es la historia de sus vidas. Luke (1995: 14) sostiene que “Los textos son los medios e instantes actuales a través de los cuales las identidades en disputa y socialmente construidas, o su subjetividad se construye y reconstruye [...] Es a través de estos textos que uno aprende cómo reconocer, representar y 'ser' [una académica, una feminista, una activista] (las cursivas son mías)". Sin embargo, en términos de una metodología critica "Una de las tareas principales del análisis del discurso es el 'desarticular' los textos cotidianos de la vida como un ejercicio de 'interrumpir el
Revista Internacional de Culturas y Literaturas, abril 2011

sentido común' acerca de la naturaleza de lo inevitable que son las identidades, valores y conceptos y que son muestra del poder en actuación y del interés material de los que parecieran ser textos inocentes" (MacLure, 2003: 9). Lo que me parece interesante en esta investigación es la conexión entre el lenguaje y la subjetividad, específicamente en la manera en que las participantes del estudio se representan a sí mismas y a la vez sus identidades a través de las historias que me fueron dichas. MacLure (2003) citando a Luke (1995), sugiere que las identidades son "tejidas y entretejidas en textos": "Para el sujeto humano, los textos no son solamente algo de lo que ellos siendo 'niños', 'estudiante', 'maestro', o 'padre' emplean como parte de su rol identitario estable o fijo; estos textos son los medios reales e instantes a través de los cuales sus identidad son construidas y disputadas, o subjetivadas, se forma y transforma [...] Es a través de estos textos que uno aprende a cómo reconocer, representar y 'ser' por ejemplo, un 'rapero', un 'estudiante con capacidades especiales', un 'americano con lealtad', o aun para ese caso ser un miembro de la 'Generación X'” (Luke, 1995: 14).

Así es que las historias de vida provistas son los textos a partir de los cuales sus vidas se construyen. De nueva cuenta me refiero a lo que sugiere MacLure: “En todas las historias de vida, el pasado tiene que ser reconstruido desde la posición de ventaja del aquí y el ahora. Esto no es solo un asunto de amarrar eventos a lo largo de una línea de tiempo sino de ensamblar los particulares de la experiencia a tal grado que puedan situarse juntas como una narrativa continua. Esto es por lo menos la convención que prevalece en las formas autobiográficas de 'occidente'... Una de las implicaciones de esto es que se tienen que decir los cambios de dirección, ambos como una discontinuidad... y como un cúmulo de eventos. Por lo que las transiciones, asi como se dicen, son algo paradójicas - se localizan en puntos específicos de tiempo y espacio, pero siempre son apartadas del momento presente y remitidas a sus orígenes en el pasado para ser significativas hacia el futuro" (1996: 274). Los investigadores de las historias de vidas y sus informantes producen textos, "Sus relatos son siempre fabricaciones en la que tejen algo nuevo pero que son ensamblados de fragmentos y recuerdos de otras fabricaciones tales como son los 'datos' de la entrevista y de las notas de campo, así como también rastros desperdigados de innumerables textos culturales de la identidad, de las políticas, de la vida institucional, de la carrera, de currículo y demás cosas" (Ibíd.: 127). Sin embargo, aunque las narrativas textuales se conciban como 'fabricaciones' cuando no hay una "versión única y verdadera de la vida de una persona, esto no significa de acuerdo a lo dicho por Travers (1991), que no hay tal cosa como el yo mismo, o de que nos sentimos menos único y lleno del yo, solo porque no podemos trazar líneas claras alrededor del yo, o el señalar por primera vez en palabras quienes somos" (MacLure, 2003: 131) 
Esta manera de acercarse al 'texto' de la vida de las personas de una forma analítica e interrogatoria podría ser contradictoria a los valores con los que se casa la metodología feminista tradicional cuando el investigador comparte una relación muy respetable con sus participantes. Aunque un acercamiento más escéptico hacia las historias de vidas no es necesariamente irrespetuoso, requiere que el que investiga reconozca los puntos de vista divergentes entre el que investiga y los que participan. La solución que propone Ryan a este dilema es: "Aceptarse uno mismo como una construcción parcialmente feminista puede contribuir en las feministas a aceptar la diversidad de las experiencias y resistencias de otras mujeres y comprender las acciones de otras mujeres. También ayuda a las mujeres feministas a encontrar puntos de convergencia con mujeres que rechazan la etiqueta de 'feminista'” (Ryan, 2001: 109). Esta perspectiva resulta atractiva porque el objetivo es el entender e interpretar las experiencias y articulaciones de la mujer académica mexicana. Sin embargo y tal como lo señala Weedon (1997), esta subjetividad está sumida, subyace, en el mundo material y se requiere de una fuerte persuasión política para inducir alguna transformación

“Un posicionamiento postestructuralista acerca de la subjetividad y la conciencia relativiza la actitud individual de sí misma al hacer de esta una consecuencia relativiza la act cul individul de si misma al hace del discurso el cual se moviliza constantemente...Sin embargo, el percibir a la subjetividad como un proceso abierto al cambio, no significa negar la importancia de las formas particulares de la inversión que hace la subjetividad individual la cual se necesita para su propia participación en los procesos y prácticas sociales. Tampoco es el implicar que las estructuras materiales, tales como la familia, educación y los procesos laborales, lo cual constituye y disciplina el sentido acerca de nosotros mismos, de manera conciente o inconciente, puede cambiar exclusivamente al nivel del lenguaje. Las prácticas discursivas subyacen en relaciones de poder objetivas mismas que requieren se de una realizacion de cambio y de transformacion" (102103).

Los relatos de las académicas entrevistadas revelan que los diferentes discursos sociales han impactado directamente en sus sentidos del ser que son los que dan cuenta acerca de su subjetividad. Más aun, esos discursos prácticos son los 'barandales' en los que ellas depositan su confianza de manera consciente o inconsciente y en estos anclan su sentido del ser cuando surgen las dificultades en sus vidas. Así pues, han podido continuar con su proyecto de vida pero probablemente dan cuenta de sus éxitos de maneras muy diferentes a mi perspectiva como investigadora feminista postestructuralista. De todos modos reconocen que no han reflexionado seriamente en este proceso y su jornada a la hora de ser académicas exitosas. Por supuesto que fueron capaces de identificar sus dificultades y admitir que en la mayoría de los casos fueron víctimas de injusticia social y que no hay nada que puedan dar por hecho.

Bell Hooks sostiene que es cuando el sujeto se ubica en el margen que puede habla porque "Desde un espacio en el margen es cuando soy diferente, cuando veo las cosas
Revista Internacional de Culturas y Literaturas, abril 2011

de diferente manera" (1990: 152). Foucault argumenta que "Las relaciones de poder se fijan de tal manera y a la vez perpetuamente asimétricas que permiten solo un limitado margen de libertad" (1979). Algunas feministas lo toman con escepticismo y critican a Foucault por ser irrelevante en cuanto a lo político. Sin embargo y tal como lo sugiere McLaren: “Las feministas sostienen de que la teoría de Foucault en relación al poder tiene como consecuencia un sujeto determinado por las fuerzas sociales más allá de su control. De hecho el impacto del trabajo de las genealogías de Foucault por reconocer fríamente de que su análisis es correcto; somos en gran manera determinadas por fuerzas que rebasan nuestro control" (McLaren, 2002: 23). Este punto de Foucault me interesa para esta investigación sobre las académicas y el desarrollo de su subjetividad porque los datos parecen demostrar (detalles en capítulos más adelante) que las normas sociales son las que han impactado fuertemente en su subjetividad al punto de que son las normas las que controlan y regulan sus conductas, creatividad y productividad. Además, sostengo que la mayoría de las académicas no lo advierten, es decir no están consciente de ello. Casi caigo en la trampa de que como sujetos son capaces de dar cuenta de su subjetividad ya que fueron conscientes de los pasos que siguieron y las decisiones que tomaron en relación a sus vidas, su futuro y sus familias. Son académicas que se posicionaron por encima del promedio y en gran manera, han controlado el curso de sus vidas. Sin embargo cuando se les interrogó acerca de qué fue lo que motivó y las impulsó hacia delante en vez de claudicar o renunciar, sus respuestas fueron muy simples tales como "Solo sabía que tenía que seguir luchando, capitular no va con mi vocabulario". Lentamente me fui dando cuenta de que tenía que darle una explicación más profunda al tema de la subjetividad individualmente, y en relación al grupo no suponían ofrecérmelo simplemente por el hecho de que se los estaba pidiendo! Creo que esto va más de acuerdo con lo que MacLure sugiere cuando cita a Walter Benjamin (1978) en relación a esos momentos de "iluminación profana". Una revelación que me estremeció tardíamente pero fue crucial para entender la naturaleza y la evolución de este proyecto de investigación.

\section{Negociando LAS RELACIONES CON LOS SUJETOS Y LOS LECTORES}

Aprender a escribir equilibradamente con algo de pasión como investigadora fue un gran desafío. Me disgustaba la idea de cómo me percibían los demás de acuerdo a la revisión teórica que inicialmente produje. Mi supervisora identificaba un tono un tanto enjuiciador, además, estaba luchando con una confrontación que se originaron como consecuencia al haber puesto mi confianza extrema en el discurso Humanista; más aún empezaba a percibir a la academia mexicana incluyendo la mía propia desde una perspectiva cultural diferente. Empezaba a entender las experiencias pasadas. Es decir las de 1985 en los Estados Unidos en la Universidad de Nuevo México fui confrontada con experiencias de doble estándares en relación a la justicia social y la moralidad que 
prevalece en esa país pero siendo incapaz de atribuirle lo político o lo filosófico. Todo lo que experimenté fue de desagrado y disgusto de manera vaga e imprecisa pero suficiente para hacerme regresar a México más pronto de lo que inicialmente estaba planeado. Es hasta ahora que empiezo a entender estas experiencias. En un segundo borrador de mis ideas las cuales mi supervisora categorizó más bien como una revisión de la teoría al intentar redactar y juntar algunas ideas y argumentos. Sus comentarios me enfrentaron a otros desafíos los cuales se centraron más en temas relacionados a la redacción. Por ejemplo sus comentarios como "Viertes muchos comentarios interesantes pero no entiendo a dónde quieres llegar de manera total o específicamente", "haces demasiadas generalizaciones", "saltas a conclusiones temáticas y lógicas", "estereotipas en blanco y negro a los agentes en vez de entender que el panorama es más complejo", "polemizas sin mayor sustancia", (Reporte: "En búsqueda de la identidad en la teoría crítica feminista de la educación y sus placeres" Diciembre 16, 2002). Otra fuente que me generó ansiedad fue la relacionada a los tipos de relaciones que se dieron entre mis colegas y entre ellas y yo. Tal como escribe Maynard (1994: 80) acerca de la reacción de sus participantes: “Constantemente me recordaban de los cambios suscitados en mi historia. Por ejemplo, uno de los comentarios más pertinentes en general de toda investigación sugiere que advierten una marcada diferencia: “Está muy bien contigo porque no estás casada y puedes darte el lujo de ciertas cosas por ti misma, ganas bien, tienes tu propio departamento y mucha ropa, no tenemos acceso a eso nosotros, dónde encontramos un empleo tan bien pagado como el tuyo... Ser enfermera si corres con suerte y todo mundo sabe lo mal pagada que somos, no te alcanza el ingreso para vivir bien...no te das cuenta de lo afortunada que eres...tu no le soportas a nadie, nosotros no podemos darnos eso, ¿qué crees que nos pasaría si somos tan atrevidas como tú? Nadie nos dirige la palabra...y nos aplican la ley del hielo". Este es casi la misma manera en que me perciben mis colegas. Algunas veces creo que más bien me envidian. Se refieren a mí como la chica 'fresa', "tu puedes desafiar al sistema porque no necesitas el trabajo, eres una niña de 'papi', una privilegiada, una 'posh"'. Siempre me ha dado tristeza esta opinión y hasta cierto punto me genera conflicto, porque yo sé que mis padres nunca me apoyarían si me quedara en casa sin hacer nada. De hecho, ellos saben que tuve que mantenerme para sostenerme durante mi carrera, haciendo todo tipo de trabajos desde trabajadora doméstica, de mesera cuidando niños, y también como traductora e intérprete. Mis padres siempre creyeron que la educación que me dieron en un principio fue suficiente, un secretariado bilingüe, así que si yo quería estudiar más correría por mi cuenta y eso lo han sostenido siempre, así que no me quedó otra sino trabajar duro para superarme. Estos fueron algunos temas que tuve que considerar antes, durante y después del trabajo de campo. Por ejemplo, en un principio cuando le pregunté a dos de mis colaboradoras a que participaran en mi investigación, ninguna de las dos me respondió. Aunque una me desafió a
ISSN: 1885-3625

ser más consistente en mi manera de acercarme a ellas y ser más diplomática. Aqui enfrenté la necesidad de aprender qué era lo más aceptable y qué no si de todos modos quería aplicar esta metodología un tanto íntima a la hora de investigar a los sujetos. Una vez que como investigadora tomé distancia de mi contexto, me convertí en una espectadora de todo tipo. Sin embargo mantenía la asociación, la conexión en una frontera donde todavía sentía que pertenecía a ese lugar. Desde ahí, necesité aprender cómo desplegar nuevos discursos y prácticas de investigación de manera estratégica. Moverse del margen al centro de la institución y esa comunidad académica, es un movimiento que requiere un talento especial y ser estratégica ya que sus participaciones para esta investigación eran cruciales. Me requirió de mucha diplomacia para llegar a las participantes y pedir su colaboración ya que las presioné a que abrieran la puerta y develaran lo privado y lo personal de sus vidas. Luego entonces las relaciones de poder con mis investigadas siempre estuvieron en constante negociación.

\section{CAMino AL PRIMER ENCUentro dURANTE EL TRABajo De CAMPO}

Para presentar la propuesta del proyecto a quienes tenían que participar con sus historias de vida fue un proceso largo y lento. Inicialmente pensé en invitar solo 6 participantes o quizás hasta 8 pero después decidí más bien contactar o las más que fueran posible durante el viaje realizado para el primer encuentro. Las informantes seleccionadas fueron académicas de carrera en la enseñanza en la educación superior en Tabasco y en la ciudad de México y solo conocía a algunas de ellas personalmente. Me aseguré que todas tuvieran un doctorado y también si tenían trabajos publicados los cuales pudiera yo usar en la investigación Una de las estrategias emprendidas fue el contactar a aquéllas académicas con doctorado fue preguntando directamente con los directores de las divisiones académicas y facultades que me dieran los datos de aquellas que reunían el perfil de doctorado. Otra estrategia fue el preguntarle a las amigas en la universidad. Una a una me fue llevando a la otra al grado que pude contactar y calendarizar entrevistas por teléfono llamándoles desde la Gran Bretaña y por correo electrónico. También busqué información en la coordinación de investigación y postgrado y allí me dieron datos de otras colegas que podía contactar e invitarlas a participar y colaborar en mi investigación.

También me puse en contacto con el departamento de recursos humanos y los departamentos de investigación para que me proporcionaran una lista de académicas con perfil académico de doctorado. La lista incluía colegas de diferentes disciplinas en diferentes facultades. Una vez que obtuve los correos electrónicos les escribí participándoles de manera directa la necesidad de su colaboración. En principio me presenté con ellas y les expliqué el tema de mi investigación y la metodología ya que se trataba de recolectar información de sus historias de vida y para esto necesitaba 
entrevistarlas y grabar sus relatos. Les presenté una propuesta del tema a investigar e cual incluía el compromiso de tratar sus vidas y sus relatos con respeto e integridad. Posteriormente, al correr la voz, una colega sugirió que debía contactar unas cuantas más y ya de allí el número de las participantes aumentó al punto que logré entrevistar a por lo menos 15 académicas ubicadas tanto en Tabasco como en la ciudad de México. En todos los casos me presenté y luego les solicité su participación y programamos la fecha para la entrevista. Fue verdaderamente conmovedor el ver que la mayoría de ellas aceptó participar aun cuando ni siquiera me conocían, esto verdaderamente fortaleció la confianza en mí misma. Ya para cuando finalmente las conocí, me sentí más en control y motivada por el desafío de conocer a estas académicas.

Lo que Goodson (2001:30) sugiere es que se empiece las historias de vida con una línea de tiempo como inicio porque invita a las "participantes a construir eventos claves de sus vidas dando énfasis en esas experiencias que se relacionan con el enfoque del proyecto". Además, las líneas de tiempo son las fuentes principales desde donde se pueden identificar los temas y así formular preguntas másespecíficas y obtener la historia de vida más completa. Los temas de mayor interés a explorar fueron aquellos relacionados con Las condiciones o factores que mantienen a las académicas constreñidas de desplegar una identidad pública de la intelectual, es decir, entender qué las reprime o impide el alcanzar más éxitos y posicionarse en esos espacios políticos. Sus fuentes de placer y qué las mantiene motivadas. Anteriormente expresé que me habían señalado que el tono en relación a algunas de mis participantes sonaba demasiado enjuiciador. Esto provocó que me analizara más detenidamente. También me di cuenta de que necesitaba comunicarle al lector mi comprensión del contexto de la académica mexicana. En México se les percibe a las académicas como "vacas sagradas" o "gurúes" (Altbach 2003, Gil-Antón: 43). Así que la sola idea de mi intento por hacerlas mis colaboradoras para la investigación a realizar y poder obtener el grado de doctorado casi me paraliza. Las académicas mexicanas no me son gente extraña toda vez que yo misma soy "académica" porque soy profesora en una universidad pública en México, la UJAT. Pero la percepción de quién es quién en la academia mexicana difiere mucho de la impresión que prevalece en las universidades occidentales. Sobre éstas Gil-Anton (2003) sostiene que "Los profesores son de tiempo completo y ostentan el grado de doctorado". Me he desempeñado como profesora por más de 15 años en la universidad de Tabasco, México y algunas de mis colegas son doctoras y muchas han estudiado en el extranjero. Son profesoras y la percepción que la mayoría tiene es que son una elite que excluyen a otras de su círculo.

De hecho, nunca he sido miembro de su club, "gurú o vaca sagrada" aunque algunas son amigas cercanas. La percepción general es que menosprecian a aquellas que no
RSSt 1885-36cional de Culturas y Literaturas, abril 2011

consideran sus iguales porque no han demostrado ser exitosas en lo académico. Esto por supuesto que es muy sutil pero se manejan con un código rojo el cual aplican para excluir a otras y a eso se le suma la tensión que de por sí prevalece en los diferentes círculos académicos. El perfil intelectual de un profesor o académico en la educación superior en occidente tradicionalmente ha sido el de doctorado, indistintamente del género, y de hecho todas estas académicas han imitado este ejemplo al que también me incluyo. Esta percepción la adopté desde mi primera experiencia del pasado cuando estudié mi licenciatura en los Estados Unidos ya que todos mis profesores eran doctores. Ellos fueron gente muy abierta a toda clase de estudiantes y recuerdo que el primer aviso que nos daban era que apreciaban de que al dirigirnos a ellos lo hiciéramos usando su nombre de pila o su apodo y evitáramos llamarlos Dr. " $\mathrm{X}$ " o Profesor " $Y$ ". Eran amistosos y muy abiertos al contrario de lo que son en México donde me topé que estas académicas son evasivas, distantes y muy sensibles a la crítica. Por ejemplo recuerdo como el Profesor Tickle representó su seminario taller como sus "2 millas a la ciudad" como algo muy práctico y los materiales documentales que presentó demostraron el potencial de emplear las historias de vida como la metodología para mi investigación. Ese conjunto de materiales que exhibió como el mapa del camino que siguió con todo el "millaje" que ya había caminado para llegar a ser el Profesor y académico que era en la actualidad. ("Me recordaste de las 140 mil millas que marca el marcador de millas de mi carro, y realmente creo que ya está para el deshuesadero. ¡Ivor (Goodson) y yo estamos de acuerdo en esto de que nosotros más bien estamos ya en esa categoría! ¿Así que donde queda tu relato de 'victoria'? Me da gusto que uses toda la información como tu quieras"). Fue su respuesta cuando le pedí permiso para citarlo desde los datos del relato de su historia de vida de la entrevista que le hicimos en el seminario taller que nos impartió a los candidatos a doctor. Pero también mi comprensión no me daba para entender si las académicas mexicanas estaban calificadas porque tenían un doctorado, no eran tan efectivas o exitosas para publicar sus investigaciones y escribir como mis profesores lo hacían en los Estados Unidos donde estudié la licenciatura en comunicación y letras inglesas, es decir, de acuerdo al estándar más bien las veía como unas fracasadas en vez de exitosas.

La impresión que tengo es que son muy contradictorias y superficiales. Para complementar esta impresión me encontré con la lectura de Octavio Paz acerca del perfil psicológico que los mexicanos tenemos en su "Laberinto de la Soledad" (1961) y tuve claridad más bien que las académicas eran solo "corazones desapasionados, ocultando su desdicha... [Canción popular]" (29) y se presume de que son iguales a todos los seres humanos en el sentido de que "Se cierran del mundo externo para protegerse de tal manera que en su rostro solo vemos máscaras al igual que su sonrisa" (Ibíd.: 29). Es así como empecé a apreciar que esa era una máscara más, otro hilo entretejido en el tejido de sus identidades académicas. 
Debo admitir que estos temores eran fuertes a que me provocaran una parálisis pero más en el fondo sabía que más bien se debía a poca confianza que tenía en mí misma. ¿Cómo es esto, cómo llegué a pensar esto si en el pasado mi sentido crítico me ha llevado a escenarios en los que he tenido confrontaciones abiertas y disputas con $\mathrm{mi}$ rector - quien por cierta era un doctor en derecho y un político quien había precedido la comisión de los derechos humanos- y el director de mi escuela en Tabasco, México con mucho éxito, con mucha asertividad y una fuerte determinación? Esto era ilógico. La diferencia con estas académicas radicaba en el hecho de que para ellas yo era una extraña, ellas eran las Otras, (doctoras, gurús, vacas sagradas) en tanto que yo era solo una candidata a doctora.

Para poder cumplir con los objetivos de esta investigación ahora tenía la necesidad de relacionarme con estas "garúes" pidiéndoles que colaboraran compartiendo la historia de sus vidas y se abrieran en lo personal y quizás hasta lo privado de sus vidas a una extraña, a alguien extraña y foránea. Pecata minuta, un menor esfuerzo con 3 de ellas a quienes consideraba amigas personales pero la actividad implicaba entrevistar a 15 por lo menos, así que aunque sabía que había otras doctoras en la universidad, para mi ellas eran las Otras, las "vacas sagradas", gente intocable y casi inalcanzable. Qué desgracia, me sentía atrapada y hacia donde volteara en la literatura lo mismo seguía impactándome porque según la teoría la tarea era realmente fácil y esto me garantizaba el éxito si tan solo seguía las instrucciones: paso uno - prepara un cuestionario de preguntas; paso dos - gánate la confianza de tus informantes, cuida el rapport; paso 3 - haz una prueba piloto; paso 4 - asegúrate de traer siempre una grabadora extra y por favor hazte un favor, asegúrate de prenderla. Si ese era el caso, ¿por qué toda esta ansiedad? Quizás porque ese era el momento de la verdad para mí y de pronto me ví confrontada con mis limitaciones, sin tener a donde hacerse y si más bien enfrentarme a la tarea. “Qué podría ser lo peor que pasara?” pensé. ¿Que me rechazaran y regresa con las manos vacías de mi viaje con el trabajo de campo o quizás que me hicieran demasiadas preguntas acerca de mi investigación y me viera forzada a confesarles que me encontraba en el proceso de construir un enfoque?

El proyecto piloto fue relativamente fácil y eso fortaleció mi confianza. Otro momento fue cuando me puse en contacto con las participantes prospectas por correo electrónico y por teléfono y estuvieron de acuerdo a darme la entrevista. No podía dar crédito y a la vez me sentía complacida porque de hecho me sugirieron otros nombres de colegas que debía incluir en mi lista porque me aseguraban de que les gustaría contribuir con mi investigación. Como que de pronto las palabras de los profesores Goodson y Tickle durante los cursos de verano del 2003 tuvieron sentido: “Les encantar hablar y hablar una vez que empiezas a preguntarles acerca de sus vidas. Tienes que cuidar más bien el tiempo porque no tienen para cuando parar".
ISSN: $1885-3625$

Quizás otra razón por la queinicialmente tenía un tono enjuiciador se debía a mi propia experiencia. Siempre he percibido que la organización me ha marginado y excluido siempre del centro de acción y han impuesto y forzado su agenda política para que más bien me someta a sus exigencias y sirva a sus intereses. Las relaciones de poder en un contexto mexicano son muy conspicuas de tal suerte que mi resistencia siempre me ha posicionadocomola extrañaoenelmejordeloscasosenlosmárgenes. Tal vezesoexplique miresentimientoyenojoen contradelainstitucióndondemehesentidoexcluiday aislada. El realizar esta investigación me ha permitido detenerme un poco y considerar mi propio posicionamiento. La dificultad quizás se deba a mi necesidad de presentarme ante los demás como alguien congruente cuando en realidad soy alguien que se constituye y reconstituye constantemente. Lo mismo les sucede a mis colegas colaboradoras. Necesitaba un discurso que fuera más tolerante, comprensible y flexible para esto. No estaba muy consciente de esto en el pasado y tampoco mis colaboradoras, es por eso que raras veces entendíamos y ni siquiera registrábamos que evolucionamos en la comprensión porque somos sujetos que evolucionamos. Ahora me doy cuenta que solo improvisaba y algunas veces reaccionaba de manera grotesca o excéntrica.

El proceso de esta investigación me ha introducido en un espacio de estar dentro y en ambigüedad. La investigación cualitativa no es un proceso tranquilo sino más bien está en constante movimiento e interrogatorio es por eso que todos estos temas me lanzaron a una búsqueda de relaciones cercanas con colegas académicas a quienes de por sí las percibía como extrañas y distantes hasta ese entonces. Ellas como personas bajo investigación tenían expectativas de lo que obtendrían por su esfuerzo y como investigadora tenía que ofrecerles algo para compensarlas por su colaboración. Elcomunicarlosobjetivosdelainvestigaciónyelusoquecomoinvestigadora le daría a los datos recolectados quizás motivaba a las participantes en ser más abiertas y receptivas hacia mí. Debo mencionar que la mayoría tuvo una buena impresión acerca de mi investigación y todavía más cuando les compartí que estaba realizando mi doctorado en la Gran Bretaña. Fueron espléndidas con felicitaciones y me desearon lo mejor y más aún me ofrecieron contribuir en todo lo que fuera necesario. En realidad, el desarrollar la confianza entre la investigadora y las investigadas no es un oficio fácil en un contexto mexicano, porque no existe la tradición de comunicar a los demás e informar acerca de lo que haces y menos involucrar a otras de manera personal o institucional. Estas son algunas de las argucias aplicadas para mantener a las mujeres a distancia y alienadas al grado de que el ambiente se percibe inseguro, amenazante y peligroso A veces se declara una guerra abierta entre aquéllos que adoptan una identidad "intelectual" y aquéllos que se involucran más en una actividad administrativa. E resentimiento de las académicas se debe a que los administrativos están ahí para hacer que las políticas, normas y reglas se cumplan, pero pertenecen a una 'nomenclatura' y por lo general no rinden cuenta a nadie. Además, muchas investigadoras como yo 
un trabajo demasiado estresante el tener que negociar con reglas y políticas que se deben observar.

La competencia es otro factor que no permite necesariamente una atmósfera de armonía. Vale aplicar la analogía de los cangrejos rojos en una cubeta porque se aviene bien a la cultura mexicana - ya que no puedes salir de esto, entonces te impido salir echándote para abajo. Esta dinámica no puede desdeñarse al tratar de hacer investigación. Cuando llegó la hora de la verdad, para mi sorpresa, las informantes estuvieron más que dispuestas a participar, aunque sus historias estuvieron repletas de 'relatos de victorias', para lo cual no estaba preparada porque fue una información bastante superficial y no se prestaba para un análisis más profundo. Así que fue necesario hacer un segundo viaje para recolectar más información. Ya para entonces nos conocíamos mejor y las cosas se facilitaron más para realizar un grupo focal. En la primera vuelta la información se apegaba más a lo que MacLure describe más bien "La gente los emplea (los relatos biográficos) para dar cuenta de su presente y definir su relación con los otros, para defender sus actitudes y conducta" (1993: 320). También transpira que en el fondo todavía quería darle un trato de 'texto sagrado' a las historias de su vida en vez de 'autobiografías mundanas' (MacLure, 1993: 373). Nuevos temores y pensamientos negativos me embargaron cuando percibí el riesgo de exagerar en una crítica analítica y vulnerar la confianza que me otorgaron las informantes. Nuevamente caí en el dilema del extraño y lo cotidiano o doméstico al tomar distancia del texto y los sujetos. Sigo sin tener respuestas 'reales' para esto y resolver esas ambigüedades y dilemas. La investigación educativa para mi se asemeja a un ejercicio de "escribir ficción bajo juramento" (Bridges, 2003: 171).

La memoria oculta lo que la historia olvida, sostengo. Hay muchas razones porqué la memoria le sirve a la historia. Los textos de las historias de vida "Existen en algún lugar entre la historia y la memoria," (Tierney, 2000: 537) y Goodson argumenta, "Todas las historias son memorias así como todas las memorias son historias" (2001: 45). La memoria puede ser como una caja de Pandora de tal suerte que cuando se abre, puede exponer un yo dividido o fragmentado el cual por lo general reside en el subconsciente. Cuando hay recuerdos dolorosos, la gente prefiere ocultarlos, ignorarlos $\mathrm{u}$ olvidarlos. Sostengo que por lo general todos preferimos olvidar las experiencias que nos causaron dolor o sufrimiento. En algunos casos podemos enfrentarlas mientras que otras más bien son recuerdos que al paso del tiempo se presentan en forma de amargura o resentimiento. El rol de la investigadora es el guiar al investigado a "Construir sus memorias desde una memoria compartida con el presente. Las memorias se recuerdan porque son importantes para uno - el emisor el entrevistador - en gran manera porque las definiciones del contexto inmediato lo
Rest.

constituye la identidad, la sociedad y la cultura" (Tierney, 2000: 545). El objetivo de esta investigación, por lo tanto, no fue es de encontrar la 'Verdad' sino más bien entender e interpretar lo que da cuenta de cómo se desarrolla la identidad al reconstruir y analizar datos de unos relatos. MacLure (2003: 23) sostiene que, "El análisis del discursos necesita realizar dos acciones por lo general incompatibles. En principio necesita apegarse a los detalles particulares de textos particulares...sin preocuparse por el tejido de las 'palabras' en las que se entretejen los argumentos. Pero, seguidamente, analizar es un asunto de distanciarse de los detalles acerca del texto específico - de alejarse y acercarse a partir de otros textos, de otros tiempos, y tratar de asomarse a un tejido más extenso de asociaciones intratextuales de entre los cuales se suspende cada texto". En mi investigación anterior esto también estuvo cargado de grandes riesgos. En un principio me aventuré a una investigación educativa aplicada en una tesis de un programa de maestría en educación superior. Esto contribuyó significativamente en mi desarrollo personal y avance de mi carrera académica, pero el proceso de análisis fue catártico, sin exagerar, tanto para mí como para mis participantes. En esa ocasión como en la actual, hubo una gran tensión y más aún resistencia de mi parte porque sentía que estaba traicionando a aquellos que habían abierto sus puertas a que entrara una extraña. Posteriormente cayeron en cuenta que eventualmente una extraña entró para hacerlos vulnerables y socavar sus políticas y normas, o peor aún moverles el tapete para derribarlas prácticamente. En mí como investigadora externa sentí una gran pérdida ya que eran mis amigas y colegas y ninguna estuvo preparada para enfrentar el nivel de incomodidad que sobrevino. Quizás por la misma necesidad de dar cuentas y ser transparente no fui acomodaticia de acuerdo al contexto en ese entonces. Está claro que "No hay nada inocente en aquello de hacer visible lo invisible" (Strathern, 2000: 309). Es por eso que la realización de investigación crítica es un tanto peligrosa, de todos modos es productiva porque trae a la luz lo invisible, al exponer y desenmascarar los diferentes temas que subyacen en el interior y el corazón de las organizaciones sociales tales como las universidades.

En esa ocasión el análisis de datos consistió principalmente de una correlación estadística y de opiniones. De todos modos se dio una construcción de nuevo conocimiento y las hipótesis cambiaron porque fue una hipótesis negativa. Pude tener una mejor comprensión de estas contradicciones acerca de esta escuela donde se daban ciertas prácticas aceptables en la normatividad de forma natural e inviolable. Sin embargo en la investigación actual, los datos resaltan las oposiciones y las contradicciones que dan cuenta de lo que Weedon (1997) sostiene acerca de la formación identidad -que la identidad es fragmentada, constituida y reconstituida cada vez que hablamos y pensamos. Inicialmente este concepto fue de mucho dilema y polémico y se generó una gran resistencia porque inicialmente era necesario romper con hipótesis y prejuicios preconcebidos. El concepto original con el cual se emprendió 
esta investigación fue con una idea un tanto naïve ya que se pensaba que la formación de la identidad era un proceso coherente y consistente y no se comprendía y por lo mismo se hacían juicios apresurados acerca de las creencias, actitudes y acciones de las informantes porque fueron surgiendo como inconsistentes en las entrevistas. Esto pudo advertirse y fue una ruptura clave que aconteció durante la etapa del análisis de datos. Sin embargo experimenté un sentido de pérdida porque el poner fin a este movimiento de asomo y distanciamiento a través del cual toda identidad, incluyendo la propia se forma y se transforma. Tal como lo sostiene MacLure, "Es durante ese incesante tránsito entre el yo y el otro que las identidades surgen y se desvanecen, hacer conexiones, y construir argumentos acerca del quien soy 'yo' y cómo me presento ante los demás, pero siempre hay una resistencia de abandonar esas posiciones fijadas sobre la presencia porque los tirones opuestos que reclama la otra identidad misma que ha sido silenciada y suplantada para que habite en ella la presente" (1995: 27).

¿Cuánto debe compartir el investigador acerca de los objetivos a alcanzar en la investigación? Esta es una tarea extremadamente difícil y desafiante para una investigadora inexperta y en particular con la investigación cualitativa donde los mismos objetivos cambian en relación al contexto y el propio desarrollo personal. Además, la información que necesitaba de estas académicas suficientemente bien establecidas era íntima, personal y privada. Su capital social y cultural respecto a mi me posicionaba como una extraña de tal suerte que el único aspecto que da cuenta de mi adscripción es que pertenezco a la misma universidad. Con aquéllas perteneciente a otra institución, ser miembro de la academia me legitimaba como colega/académica. El estar hablando con académicas de experiencia me introdujo en un nivel académico al cual no estaba acostumbrada. Mi objetivo fue el de teorizar a partir de sus experiencias de vida al motivarlas a que se expresaran acerca de sus procesos personales explicando cómo habían alcanzado sus éxitos aparentes, cuáles eran sus fuentes de placer y contentamiento pero también sus luchas; en otras palabras, hacerlas que revisitaran su pasado en una introspección y reflexión. También esperaba que a través de una autorreflexión crítica acerca del tejido de su contexto y de sus propias vidas pudiera darse alguna transformación durante el proceso, en particular en aquéllas sobre las relaciones de poder y de los cuerpos colectivos. Esto fue más que un propósito un deseo ya que este proceso involucraba algún tipo de confianza intelectual y empoderamiento político que se sale de los límites de la cobertura de un proyecto doctoral. Aun con objetivos modestos, esto más bien resultaba en un desorden y proceso doloroso ya que los riesgos implicaban que la conversación espontánea les hiciera recordar memorias desagradables y tristes imposibles de controlar y que me rebasaran como investigadora. Se realizaron todas las entrevistas una por una pero la primera fue crucial ya que se trataba de una amiga. En mi agenda anoté que aunque llegué a tiempo a la entrevista, ella se encontraba con alguien y preguntó que si podía
ISSN: 1885-3625 ar de Culturasy Literaturas, abril 2011

quedarse a presenciar el proceso. Mi respuesta fue de que si ella estaba de acuerdo por mí no había cuidado "No me alteré pero creí necesario preguntarle y dejar más bien que ella decidiera y si se sentía cómoda con su presencia. ¡Sorprendentemente conservé la calma y no perdí la concentración! Pasados algunos minutos, se disculpó y se marchó" (Bitácora de investigación: Octubre 2003)

El argumento sobre la historia de vida que Goodson nos presentó durante su seminario en el verano del 2003, reforzó mi confianza para realizar el trabajo de campo con una actitud más optimista y de hecho ese primer viaje de trabajo de campo fue todo un éxito ya que tuve la oportunidad de entrevistar no a 8 sino a 15 académicas en Tabasco y en la ciudad de México que en un primer momento en su mayoría eran desconocidas para mí.

Aunque la versión de sus vidas redundó en una historia de "relatos de victoria" (Lather, 1994), si dieron detalles acerca de lo bueno y lo malo, el dolor y el sufrimiento que experimentaron para llegar hasta donde están. Más aún, algunas estuvieron interesadas en narrar detalladamente y dar cuenta de sus historias de vida incluyendo a toda su familia proporcionando datos biográficos. Esto de por sí ya era todo un proyecto de muchos retos pero el cual me inundaba de interés el realizarlo.

\section{La Interpretación y la Práctica de la Ética}

Como debía asegurarme bien y estar preparada para cualquier tipo de sorpresas al realizar las entrevistas, las recomendaciones que subyacen en la literatura de lo que proponen los textos extensamente acerca del tema como Goodson (2001) en cómo realizar las historias de vida fue muy útil. Además de que se realizaron 2 entrevistas piloto. De esta experiencia algunas lecciones fueron significativas para anticiparse a los problemas que surgen con participantes reales. Uno de los hallazgos se relacionaba en cómo enfrentar las emociones cuando las que participan comparten detalles íntimos. Un caso tuvo que ver cuando una de ellas compartió acerca del sufrimiento que su madre experimentó al tener que adaptarse a una nueva cultura y sociedad al verse forzada a inmigrar a un país extranjero y así poder darle una vida decente a su familia y sacarlas de la pobreza. Mis temores fueron el intensificar su dolor al estar preguntando demasiado y me intrometiera en esos recuerdos privados y dolorosos. Esta idea me aterraba ya que de ninguna manera podía evitar ser responsable de la persona en investigación ya que como investigadora estaba llamada a "conducirme bajo ciertos límites éticos apropiados basados en el respeto y cuidado de la persona humana" (Bridges, 2001: 371)

La 'ética' a como la entendemos en los círculos de investigación en la Gran Bretaña no fue un asunto que les preocupara mucho a las participantes ya que no es un discurso de prioridad en la academia mexicana o por lo menos esa fue mi percepción. En vez 
de estar preocupadas por compartir su historia de vida más bien estaban emocionadas de participar y querían que sus nombres aparecieran citados en la investigación. ¿Es probable que hayan pensado que solo divulgarían información que fuera inocua? Esto si fue una preocupación en un principio que discutí con todas y cada una de las participantes por el uso que potencialmente podía darle a la información. Todas estuvieron de acuerdo de que podía usar la información como quisiera, con la excepción de Sofía quien señaló que sería cuidadosa con lo que iba a relatar y que no, lo político es estrictamente privado y personal. Esa etapa la vamos a excluir durante la entrevista". Esto no implicó por supuesto que fuera menos entusiasta de colaborar para mi investigación pero sin rebasar esos límites. ¡De hecho Sofía es una abogada de mucha experiencia por lo que era conveniente para mí más bien protegerme también o de lo contraria podía enfrentarme a una demanda por difamación, calumnia o perjurio!

Por lo contrario siento que hay ocasiones cuando una lectura crítica de las historias de vida podría ser parte de un análisis crítico pero estaba fuera de toda posibilidad de explicarles adecuadamente el embrollo a aquellas que no estuvieran informadas del contexto en que sus historias serían leídas y comprendidas. Las participantes para mi sorpresa sintieron que las entrevistas fueron para ellas una oportunidad de colaborar con mi desarrollo personal. Una de ellas señaló que "Era un privilegio el participar como tu informante y el hecho de que esto fue una oportunidad de compartirle mi historia de vida a alguien y me da mucho gusto que fuiste tu esa persona porque siento que tu investigación es muy significativa". Recuerdo que cuando entrevisté a Lorena en la sala de profesores, reconocí la presencia de una vieja conocida, Laura. Me di la oportunidad de compartirle acerca de mi investigación y la invité a participar. Ella declinó alegando que no tenía un doctorado pero que en todo caso estaba dispuesta a ofrecer como voluntaria a su amiga Ana y que era cosa de que yo se lo pidiera.

Me presentó con Ana y cuando ésta se enteró de qué se trataba mi investigación, de inmediato acepto participar y programé en la agenda la entrevista allí mismo para la siguiente semana. Por supuesto Lorena había platicado con Ana acerca de mi investigación y ya para entonces estaba bien informada a que se debía mi presencia en la división. Al reflexionar en sus diferencias, llegué a la conclusión de que había más similaridades entre Lorena y Ana, ya que ambas habían abrazado la ideología marxista en el pasado además de que ambas tenían una gran experiencia en la carrera política. Lorena sugiere que su afiliación al Partido Comunista mismo que más tarde se transformó en el Partido de la Revolución Democrática (PRD) “Me ha convertido en un elemento vulnerable a los ojos de Gobernación. ¡Así que me tienen registrada como izquierdista y revolucionaria en sus archivos!" Por lo mismo tanto las informantes como sus historias de vida necesitan protegerse y ser tratadas con cuidado y evitar
Revista Internacional de Culturas y Literaturas, abril 2011

consecuencias innecesarias. Todos estos temas me han hecho estar consciente de que la investigación siempre está cargada de todo tipo de riesgos y no siempre pueden absolverse aun con nuestras mejores intenciones. La investigación siempre tiene el potencial de convertirse en algo político aun a nivel individual ya que "Tiene un peso sobre cómo los seres humanos le dan sentido a su mundo" (Goodson, 2001: 89). Es por eso que tiene que ver con mandar un mensaje "correcto" en relación a los "hallazgos" y “la explicación teórica y la comprensión de las 'diferencias' entre...las experiencias, percepciones y las motivaciones porque pueden tener repercusiones que van mucho más allá de las circunstancias locales en las cuales se formularon" (Ob.cit.).

\section{Un Segundo Viaje de Campo y el Grupo Focal}

Un segundo viaje de trabajo de campo fue necesario ya que la mayor parte de los relatos del primer viaje sonaban demasiado a relatos de éxitos. Una de las sugerencias que me dieron fue la de o entrevistar de nueva cuenta a las participantes o el de hacer un grupo de enfoque y de dicción donde se les pidiera compartir abiertamente entre ellas, aspectos de las historias de sus vidas a partir de los temas que presentaría para discutir. Si el primer viaje de trabajo de campo fue emocionante y de mucho desafío ya que me dio mucha confianza, el segundo requería más esfuerzo y estrategia ya que el objetivo era el organizar un grupo focal y de discusión que pudiera de ser posible video grabarse. Recuerdo que ya para entonces me sentía con más optimismo y de inmediato empecé a contactar a la gente en la administración en la UJAT (Universidad Juárez Autónoma de Tabasco) y averiguar si podía reservar el estudio de televisión. El grupo focal como metodología se sabe que es efectiva y productiva ya que se anima a los participantes a que expresen sus opiniones e ideas entre ellos para de allí basarse en sus áreas comunes y sus diferencias (Denzin, 1986; Frey \& Fontana, 1993). Morgan (1998: 9) sostiene que "[los grupos focales] son una manera de escuchar a la gente y aprender de ellos". Aunque también se identifica un elemento donde se exponen y se hace visible lo que subyace y que no se menciona, especialmente en relación a las experiencias de las mujeres, "Los grupos focales pueden ser un elemento importante para el desarrollo de la agenda en cuanto a justicia social de la mujer se refiere porque es útil para exponer y validar las experiencias de avasallamiento cotidiano de las mujeres y su sobre vivencia individual y colectiva además de sus estrategias de resistencia" (Madriz, 2000: 836). Para esta experiencia nueve de ellas estuvieron de acuerdo en participar aquí en Tabasco. Fue imposible incluir las que radican en la ciudad de México y tampoco fue posible juntarlas en un grupo focal y de discusión.

La respuesta en participar de casi todas las participantes fue positiva así que tentativamente programé la sesión para el 10 de marzo del 2004. La mayoría confirmó la posibilidad de asistir, así que planeé esta actividad pensando en algunas temáticas. 
Preparar esta actividad me requirió considerar todos los detalles tales como las preguntas y los temas que suponía usar para generar la discusión. Ya para entonces estaba más consciente de un mayor reto: el de enfrentarme a la cámara de televisión. Aquí no se trataba de hacer análisis del lenguaje corporal sino el contenido de sus argumentos con la ayuda de un medio visual. Pero antes de entrar en detalle con esta experiencia debo señalar que esta actividad finalmente se realizó extramuros y no en el campus donde se disponía de un estudio de televisión y más bien contratar los servicios de un estudio profesional privado.

Brevemente hago el recuento de esta historia dramática y vergonzosa. Aun cuando la coordinadora del centro de comunicación y mercadotecnia (CECOM) había confirmado por teléfono desde la Gran Bretaña la reservación del uso del estudio para una fecha específica, cuando llegué a Tabasco, fui confrontada con una realidad diferente. La directora informalmente me dio esta noticia, "Nunca fui informada de tu reservación del estudio ya que nunca leo los correos. Segundo, ya está todo reservado para este mes y no puedo hacerte ningún espacio. Tercero, no tenemos ninguna cámara que podamos facilitarte". Casi me da un shock de la impresión y la consternación de plano, pero la solución al problema surgió de la solidaridad de quienes fueron mis colegas en el pasado ya que estuve empleada en este centro como guionista de documentales educativos. De manera espontánea, se ofrecieron para contactar a un estudiante quien podía ayudar a reorganizar todo en otro espacio. Esto realmente fortaleció mi confianza y en esta ocasión el estímulo procedió de amigos dentro de la academia. La actividad pudo realizarse exitosamente en un estudio privado y externo. Aunque algunas participantes se conocían entre sí, para la mayoría fue la primera vez en conocerse, así que el tiempo que pasamos juntas fue un tiempo de celebración de camaradería entre nuevas amigas y el rapport entre las participantes fluyó en las conversaciones casuales en que participaron con toda libertad cuando ¡todas querían expresas sus opiniones! De hecho, como moderadora, tenía que administrar el tiempo ya que todas fueron muy espontáneas y quería tratarlas a todas por igual, especialmente con aquellas que caían en la categoría de la "gurú" y tendían a monopolizar la conversación y capitalizar de sus experiencias. Así que el rol de moderara consistió en sacar de la mayoría de las participantes sus opiniones en torno a los temas que yo necesitaba cubrir.

\section{Otras Fuentes de Datos y De Información}

Además de las transcripciones de las entrevistas y del grupo de enfoque, mis diarios de investigación correos electrónicos y otras formas de comunicación con las informantes, también acudí a un amplio rango de libros y páginas en la Web y periódicos para complementar la fuente de datos. Inicialmente había considerado hacer un análisis documental y literario como la fuente principal y única de datos para esta investigación y eso incluyó también la
RSA: Internacional de Culturas y Literaturas, abril 2011

biografía y literatura de Sor Juana Inés de la Cruz, la décima musa y la primer feminista de América (Schons, 1925). En la página Web de la Universidad de Cambridge fue una fuente mayor de información de donde obtuve su poesía, "Diferencia e indiferencia: La Poesía de Sor Juana Inés de la Cruz", y un video clip de una película reciente, "Yo la Peor de Todas" (Bemberg, 1990).

De hecho, en la Universidad de Cambridge se ofrece un programa completo de literatura latino americana y Sor Juana es una de las poetas que se incluyen. Otros textos que incluí fue el de Octavio Paz (1982) “Las Trampas de la Fe”, "La Respuesta” (traducida por E. Powell, 1994) y las Obras Completas de Sor Juana Inés de la Cruz, Volumen I, II, III, IV editadas por el Fondo de Cultura (FCE, 2001), lo cual me proveyó con una biografía muy reciente y un análisis histórico mismo que pensé que sería suficiente para dar cuenta acerca de la formación de su propia identidad en medio de las ideologías que prevalecían en su tiempo. Muy pronto me di cuenta y renuncié a esta idea a favor de una investigación empírica con académicas contemporáneas. Sin embargo la vida de Sor Juana jugó una parte muy importante en cómo estaba entendiendo a la mujer académica en la actualidad y de la cual se relata en un apartado de la investigación.

Otras fuentes de literatura que influyeron fuertemente esta investigación fueron escritos y biografías de mujeres académicas e intelectuales mexicanas tales como Esther Orozco, "Si la mujer esta...Chihuahua: abriendo caminos en la lucha por la democracia" (1999); Rosario Robles, "Con todo el Corazón. Una Historia Persona desde la Izquierda (200), M.K. Schussler,"Elena Poniatowska, Elenísima. Ingenio y Figura de Elena Poniatowska" (2003); O Wornat, “La jefa. Vida pública y privada de Marta Sahagún de Fox (2003); M. Lamas, “El Género. La construcción cultural de la diferencia sexual" (1996); A. Ortiz-Ortega, "¿Si los hombres se embarazaran, el aborto sería legal?" (2001); R. Castellanos, “El Eterno Femenino" (1975); G. Hierro, “Ética y Feminismo" (2003); E. Bartra, "Debates en Torno a una Mitología Feminista" (2002); Ma. T. Torres V. y L. Romero Rodríguez, “La Educación de la Mujer en Tabasco” (1991); T. Torres Vera, "Mujeres y Utopía”, (2001); V. Rodríguez, "La Mujer en la Política Contemporánea Mexicana" (2003)

Camino de la Traducción y Conclusión

El proceso del análisis de datos ensanchó un espectro de posibilidades de ver más allá de lo visible y el espíritu de la deconstrucción fue instrumental para ponerlas al frente, a lo visible. Pero el hacer lo invisible visible significó, en mi caso, primero traducir del español al inglés. Esto fue más que un proceso de traducción literal. Para esta investigación esto fue en realidad más de un caso de traducción e interpretación intercultural. Por ejemplo, una de las tareas principales fue el localizar los discursos de mayor prioridad para las feministas e investigadoras mexicanas además de la literatura 
publicada o investigaciones realizadas en México. Una segunda tarea tuvo que ver con el análisis crítico tanto de las transcripciones como también del contexto y de ese modo abstraer en explicaciones plausibles la relación de los discursos políticos y personales a través de los cuales las participantes decantaron y cómo estos contribuyeron en la construcción de sus identidades. La tentación se asoma al querer agregar algunos datos para ilustrar mi experiencia con la institución para que el lector juzgue en ambos casos mi relación con la institución así como comprender un poco más en relación al contexto en el que realicé la investigación. El reporte de Riggs (2005) acerca de la academia en España describe las dificultades que las académicas feministas enfrentan. Recurre a la publicación reciente y controversial de Rosa Peñasco “Mobbing en la Universidad". En esta sostiene que la 'estructura absoluta' que prevalece en las universidades españolas, ha propiciado “Una cultura del acoso, endogamia y la corrupción...el problema es que todas las universidades españolas tienen la misma estructura organizacional rígida acoplada con una ausencia de rendición de cuentas" (2005: 11). Guil y Arriaga también reportan algo similar acerca de la situación que prevalece en las universidades en Sevilla, España, "La Situación de las Mujeres en las Universidades Andaluzas (2005) Las condiciones en México desde mi experiencia no son nada diferentes, y de esto reporta el Colegio de Académicas Universitarias en la publicación reciente que coordinaron Olga Bustos y Norma Blázquez Graf (2003), “Qué dicen las académicas acerca de la UNAM" y tal vez eso explique en mi caso el por qué fui humillada y hostigada cuando pedí que me otorgaran un aumento salarial al cual tenía derecho. Como siempre hago mis solicitudes por escrito de todo tengo record. Los procedimientos por lo general se toman 3 meses a lo mucho pero en México la tradición que prevalece es similar a la de España ya que se vale de los enchufes o palancas (conexiones que manipulan los hijos de influencias) o amiguismo (club de amigos) si quieres tener algún resultado positivo.

En mi caso da la casualidad que carezco de palancas o redes de amigos de ningún tipo que cuiden mis intereses, más bien solicito directamente y presiono porque se de una decisión favorable. Eso me mete en problemas desde luego ya que me resisto en renunciar fácilmente hasta que la administración agote todo lo necesario. Entre más presiono, más se retrasan. Como siempre persisto y siempre fundamento mis argumentos en la rendición de cuentas, me maltratan señalándome como alguien grosera o peor aún alguien que carece de habilidades diplomáticas. Una vez inclusive se atrevieron a amenazarme con despedirme y mi respuesta fue que si lo intentaban, los demandaría ante conciliación y arbitraje y me iría a los medios. Esto funcionó ya que me otorgaron el aumento y lo hicieron retroactivo en el 2003. Recientemente en el 2005, tuve la desagradable experiencia de negligencia incompetencia con las personas encargadas de atender todos los asuntos relacionados a los intereses académicos de los que estamos en el extranjero. Como les pedí cuentas por su falta de responsabilidad en procesar mi solicitud para extenderme el período de
RSAta Internacional de Culturas y Literaturas, abril 2011

estudios y el financiamiento y así completar mi programa doctoral, una solicitud que se toma por lo general 3 meses se tomó 7 . Esto se convirtió en una distracción y pérdida de tiempo que estorbó el desarrollo de mi investigación. De nueva cuenta fui diplomática en un principio pero cuando nadie se hizo responsable, tuve que denunciarlo con la Rectora. Como de todos modos continuaban ignorándome, intensifiqué mi solicitud hasta que reaccionaron. Ahora lo tengo claro que en cuanto a mí esto es lo normal más que la excepción para hacer que sucedan las cosas y obtener resultados. Es así como de manera relatada más que de un capítulo lleno de planteamientos teóricos áridos se intentó dar cuenta no solo del proceso metodológico que se aplicó en la realización de la investigación sobre la identidad de la académica mexicana y el camino recorrido que se aplicó en la investigación educativa desde un enfoque poststructuralista feminista sino que también se da cuenta del desarrollo personal como investigadora. En otra ocasión explicaré más detalladamente acerca del contexto general mexicano además del contexto de las universidades mexicanas y el estatus particular que guarda en feminismo dentro de estas instituciones.

REFERENCIAS BIBLIOGRÁFICAS

Altbach, P. G., The Decline of the Guru, New York, Palgrave, 2003.

Althusser, L., Lenin and Philosophy and Other Essays, London, New Left Books, 1971 Arnot, M., Reproducing Gender, RoutledgeFalmer, London, 2002.

Bartra, E., Debates en Torno a Una Metodologia Feminista, Mexico UNAM-PUEG, 2002. Bemberg, M.L. (1990). Yo la peor de todas. (Film) Argentina. http://www.latin-american. cam.ac.uk/SorJuana/SorJuanaClips.htm

Benjamin, W., Reflections (edited by P. Demetz and translated by E. Jephcott), New York, Harcourt Brace Javanovich, 1978

Blackmore, J., Troubling Women. Feminism, Leadership and Educational Change, Buckingham, Open University Press, 1999.

Bourdieu, P., Outline of a Theory of Practice, Cambridge, Cambridge University Press, 1977.

Bridges, D., "The Ethics of Outsider Researcher" en Journal of Philosophy of Education, Vol. 35, No. 3, pp. 372-386, 2001

Bustos, O. and Blazquez G., N, Qué dicen las académicas acerca de la UNAM, Colegio de Académicas Universitarias, México, UNAM, 2003.

Butler, J., Excitable Speech. A Politics of the Performative, Routledge, New York, 1997. Castellanos, R., El eterno femenino, México, FCE, 1975.

Delgado B., G., La Condición de Genero de las Académicas, Masters Thesis. Faculty of Psychology. UNAM, 2004. 
Denzin, N.K., "A postmoderm social theory", Sociological Theory, 4, 194-204, 1986.

Derrida, J., Speech and Phenomena, Evanston, Northwestern University Press, 1973.

----, Of Grammatology, Trans. By G. Ch. Spivak. The John Hopkins University Press, Maryland, 1976

----, "Some statements and truisms about neologism, newisms, positions, parasitisms and other small seisisms" in D. Carroll (ed.) The States of 'Theory': History, Art and Culture, New York: Columbia Press, 1990.

Erben, M., Biography and Education: a reader, Edited by Michel Erben, London, Falmer Press, 1998.

Faith, K., "Resistance: lessons from Foucault and feminism", in Radtke, H. I., and Stam, H. J. (eds) Power Gender: Social Relations in Theory and Practice (Inquiries in Social Construction Series), London, Sage, 1974.

Foucault, M., The Archaeology of Knowledge, Transl. by Alan Sheridan, New York, Pantheon, 1972

---, Discipline and Punish, Translated by Alan Sheridan, New York, Pantheon, Reprent. New York: Vintage Books, 1979. Originally published as Surveiller et punir: naissance de la prison. Paris: Gallimard, 1975

----, I, Pierre Rivière, Harmondsworth, Peregrine, 1978.

----, Michel Foucault: Power, Truth, Strategy, eds. Meaghan Morris and Paul Patton, Sydney, Feral publications, 1979.

----, What is an Author? Screen, 20 (1), pp. 13-33, 1979a.

----, The History of Sexuality, Volume One, An Introduction, Harmondswort, Pelican, 1981.

----, “What is Enlightenment?" In The Foucault Reader, Edited by Paul Rabinow, New York, Pantheon, 1984

----, The use of pleasure: The history of sexuality, Vol. 2. Translated by Robert Hurley. London: Pinguin,1985.

---, “Nietzsche, Freud, Marx." In Critical Texts. 3:2, 1986.

Frey, J.H., and Fontana, A., "The group interview in social research." In D. L. Morgan (Ed.), Successful focus groups: Advancing the state of the art, Newberry Park, CA, Sage, 1993.

Gil-Anton, M., "Big City Love: The Academic Workplace in Mexico", In Altbach, P. G. The Decline of the Guru, New York: Palgrave, 2003.

Goodson, I. and Sikes, P., Life History Research in Educational Settings: Learning from Lives, Buckingham, Open University Press, 2001
Revista Internacional de Culturas y Literaturas, abril 2011

Goodson, I., Professional Knowledge, Professional Lives. Studies in education and change, England, Open University Press, 2003.

Guil, A. and Arriaga, M., La Situación de las Mujeres en las Universidad Públicas Andaluzas, Sevilla, Consejo Económico y Social de la Junta de Andalucía, 2005.

Hebdige, D., Hiding in the Light, London, Routledge, 1989

Hierro, G., Etica y feminismo, Segunda edición, México, UNAM, 1998.

Hooks, B., Yearning: race, gender, and cultural politics, Boston, South End Press, 1990.

Kristeva, J. (1974a), “Oscillation between Power and Denial”, in Marks and de Courtivron (eds) 1981, pp. $137-41$.

----, “Women's Time”, Signs, vol. 7 (1), Chicago, University of Chicago Press, 1981.

----, The Kristeva Reader, Edited by Toril Moi. Oxford, Blackwell, 1986.

Lacan, J., Écrits, London: Tavistock, 1977.

Lamas, M., El Género. La construcción cultural de la diferencia sexual, México, UNAM/CH/PUEG, 1996.

Lather, P., Feminist Research in education: within/against, Geelong, Deakin University Press, 1991

----, Textuality as praxis, Paper presented to the Annual Meeting of the American Educational Research Association, New Orleans, April 1994.

Luke, A., "Text and discourse in education: an introduction to critical discourse analysis", Review of Research in Education, 21: 2-47, 1995.

Lyotard, J.F., The Postmodern Condition: A Report on Knowledge, Trans. by Bennington and Brian Massumi, Manchester, Manchester University Press, 1984.

MacLure, M., and Stronach. I., Educational Research Undone. The Postmodern Embrace, Buckingham, Open University Press, 1997.

MacLure, M., "Mundane Autobiography: some thoughts on self-talk in research contexts", British Journal of Sociology of Education, Vol. 14, No. 4. 373-384, 1993

---, “Postmodernism: a postscript", Educational Action Research, 3(1), 105-16, 1995.

---, "Telling transitions: boundary work in narratives of becoming an action researcher", British Educational Research Journal, Vol. 22, No. 3 pp273-286, 1996.

---, Discourse in Education and Social Research, Buckingham, Open University Press, 2003. Madriz, E., "Focus groups in feminist research", in N.K. Denzin \& I.S. Lincoln (Ed.), Handbook of Qualitative Research, 2nd Edition. Thousand Oaks, CA, Sage, 2000. Maynard, M. and Purvis, J., Researching Women's Lives from a Feminist Perspective, London, Taylor \& Francis, 1994.

McLaren, M. A., Feminism, Foucault, and Embodied Subjectivity, New York, State University of New Press, Albany, 2002.

Morgan, D.L., The focus group guidebook, Thousand Oaks, CA, Sage, 1998.

Orozco, E., Si la mujer esta..., Chihuahua, Doble Elice Ediciones, 1999. 
Ortiz-Ortega, A., Si los hombres se embarazaran, el aborto seria legal? México, EDAMEX, 2001.

Paz, O., The Labyrinth of Solitude [El Laberinto de la Soledad], Translated from the Spanish by Kemp, L., Milos, Y., and Phillips B., R. New York, Grove Press, 1961.

----, Las Trampas de la Fe. [The traps of faith]. México: FCE, 1985.

Peñasco, R., Mobbing en la Universidad, España, Adhara, 2005.

Rigg, P., "Spain urged to root out abuse and favouritism in academe." The Times Higher, July 2005.

Robles, R., Con todo el corazón. Una historia personal desde la izquierda, México, Random House, 2005.

Rodríguez, V. E., Women in contemporary Mexican politics, Texas, University of Texas Press, 2003.

Ryan, A. B., Feminist ways of knowing. Towards theorising the person for radical adult education, Leicester,

NIACE, 2001.

SEDESOL [Secretaria de Desarrollo Social], Gobierno de Mexico, [Social Development Secretary], 2005.

Sawicki, J., "Identity politics and sexual freedom: Foucault and feminism”, in Irene Diamong and Lee Quinby (eds), Feminism and Foucault, Boston, Mass, Northeastern University Press, pp. 177-91, 1988. Schons, D., “The First Feminist in the New World.” Equal Rights, October 31, 1925, pp. 11-12.

Schuessler, M.K., Elenísima. Ingenio y figura de Elena Poniatowska, México, Editorial Diana, 2003.

Sor Juana Inés de la Cruz, La Respuesta/The Answer, Translated by Electa Arenal and Amanda Powell, (1994), New York, The Feminist Press.

----, Obras Completas de Sor Juana Inés de la Cruz, Vol. I, II, III, IV. Biblioteca Americana. Mexico, FCE. $2001 ; 1957$.

Spivak, G. C., In other worlds: Essays in cultural politics, New York, Methuen, 1987.

Strathern, M., "The tyranny of transparency", British Educational Research Journal, 26(3): 309-21, 2000.

Tierney, W., "Undaunted courage: life history and the postmodern challenge," in N. Denzin and Y. Lincoln (Eds.) Handbook of Qualitative Research, 2nd. Edn. Thousand Oaks, CA: Sage, 2000.

Torres V., Ma.T., and Romero, L., La educación de la mujer en Tabasco, Tabasco, UJAT, 1991.

Torres V., Ma.T., Mujeres y utopía, Tabasco, UJAT, 2001.

Travers, A., "From 'normal appearances' to 'simulation' in interaction", Journal of the Theory of Social Behaviour, 21 (3): 297-338, 1991.

Weedon, C., Feminist Practice \& Poststructuralist Theory, Blackwell Publishing, Oxford, 1997.

Wornat, O., La Jefa. Vida pública y privada de Marta Sahagún de Fox, México, Editorial Grijalbo, 2003. 